\title{
Semantic context influences memory for verbs more than memory for nouns
}

\author{
ALAN W. KERSTEN \\ Florida Atlantic University, Boca Raton, Florida \\ and \\ JULIE L. EARLES \\ Wilkes Honors College at Florida Atlantic University, Jupiter, Florida
}

\begin{abstract}
Three experiments revealed that memory for verbs is more dependent on semantic context than is memory for nouns. The participants in Experiment 1 were asked to remember either nouns or verbs from intransitive sentences. A recognition test included verbatim sentences, sentences with an old noun and a new verb, sentences with an old verb and a new noun, and entirely new sentences. Memory for verbs was significantly better when the verb was presented with the same noun at encoding and at retrieval. This contextual effect was much smaller for nouns. Experiments 2 and 3 replicated this effect and provided evidence that context effects reflect facilitation from bringing to mind the same meaning of a verb at encoding and at retrieval. Memory for verbs may be more dependent on semantic context because the meanings of verbs are more variable across semantic contexts than are the meanings of nouns.
\end{abstract}

The vast majority of research on memory has focused on memory for nouns. Clearly, however, the purpose of the human memory system is not simply to remember the names of the objects that have been encountered. Instead, it seems much more important to remember what each of those objects did-in part, because it may help us to predict what those objects will do when we encounter them again. One way to test memory for the actions of objects is to examine memory for verbs. Although there has been relatively little research on memory for verbs, the research that has been conducted has generally revealed that memory for verbs is not as good as memory for nouns (e.g., Earles \& Kersten, 2000; Earles, Kersten, Turner, \& McMullen, 1999; Engelkamp,Zimmer, \& Mohr, 1990; Reynolds \& Flagg, 1976). Investigating why verbs are difficult to remember may yield a better understanding of how the human memory system represents actions.

The present research was designed to test the hypothesis that verbs are more difficult to remember than nouns because the meanings of verbs differ more in different contex ts than do the meanings of nouns. Thus, if the context at retrieval is different from the context at encoding, this may make it difficult to retrieve a verb, because the

The present research truly represents a joint effort between the two authors, and the choice of order of authorship was determined in a fairly arbitrary manner. Preliminary results were presented at the 41 st Annual Meeting of the Psychonomic Society in New Orleans. The authors thank Christian Meissner for his help with the analysis of the data. We also thank Elizabeth Dietrich, Tine Dyg, Yan Li, Elena Paraskova, Ari Rosenberg, and Scott Turner for their assistance in running this project. Please address correspondence to A. W. Kersten, Department of Psychology, Florida Atlantic University, Boca Raton, FL 33431-0991 (e-mail: akersten@fau.edu). meaning of the verb at retrieval will not match the encoded meaning of the verb.

This hypothesis is suggested by a number of theories of noun and verb meaning. One is Gentner's $(1981,1982$; Gentner \& Boroditsky, 2001) natural partitions/relational relativity theory. According to the natural partitions theory of noun meaning, nouns tend to refer to collections of percepts that cohere particularly tightly together because of Gestalt properties, such as proximity, common fate, and boundedness. These Gestalt properties encourage both prelinguistic infants and adults to perceive these collections of percepts as objects, and as a result, children have already perceived and categorized these objects by the time language learning begins. Learning such a noun thus involves simply mapping a newly presented label onto a preexisting object category. Because such nouns are defined in terms of nonlinguistic categories, their meanings are very stable despite variations in linguistic context.

In contrast, according to the relational relativity theory, relational terms, such as verbs, cannot be straightforwardly mapped onto preexisting nonlinguistic categories. This is because relations can be construed in multiple ways and, thus, experience with a language is necessary for a learner to know which of these possible construals is relevant to the meaning of a word. Learning a relational term is, thus, more of a cognitive invention than a simple associative process. Because verbs are not so tightly anchored in nonlinguistic categories, their meanings are less stable and more subject to alteration with variations in linguistic context.

Kersten $(1998,2003)$ has also proposed that the meanings of many verbs are dependent on linguistic context- 
in particular, the nouns that accompany them. Kersten proposed that the role of a manner-of-motion verb in a sentence is to select from a number of manners of motion associated with a noun. For example, the noun person may be associated with a number of different manners of motion, such as walking, running, skipping, jumping, and so forth. A manner-of-motion verb (e.g., run) may indicate which of these different manners of motion is relevant in a given situation. Because manner-of-motion information is associated with nouns in this theory, the meanings of manner-of-motion verbs may change dramatically in the context of different nouns. For example, the meaning of the verb run means markedly different things in conjunction with the nouns person, horse, car, and politician.

Finally, Kintsch's (2001) theory of predication in latent semantic analysis (LSA) also suggests that the meanings of verbs are more dependent on semantic context than are the meanings of nouns. In LSA, the meaning of a word is defined by a vector in a multidimensional space, representing the typical discourse contexts in which that word appears. In prior research with LSA (e.g., Landauer, Laham, Rehder, \& Schreiner, 1997), the meaning of a word combination was assumed to be represented by the centroid of the vectors representing the two words. Thus, when the meaning of a noun-verb pair is computed, this procedure would suggest that the meaning of the noun would be altered as much as the meaning of the verb, in order to make the two words compatible.

In contrast, in Kintsch's (2001) predication algorithm, the vector representing the meaning of a noun-verb pair is biased by including in the computation of that vector one or more semantic neighbors of the verb that are contextually appropriate for the noun. This has the effect of biasing the meaning of the verb so as to be consistent with the noun. For example, in order to compute the meaning of the sentence The horse ran, the nearest semantic neighbors of ran are first activated to the extent that they are related to both horse and ran. This tends to activate such words as raced. The vector representing the meaning of the sentence is then determined by computing the centroid of the vectors representing horse, ran, and one or more of the most activated semantic neighbors. The resulting vector is similar to the vector representing the meaning of the word gallop and is more similar than is the vector representing ran in isolation. This suggests that the meaning of ran has been altered to make it more consistent with horse. The meaning of horse also changes to make it consistent with ran, but these changes are smaller. For example, the vector representing the horse ran is more similar to the vector representing horse than to the vector representing ran, suggesting that ran has changed more than horse. Consistent with the theories of Gentner and Boroditsky (2001) and Kersten (1998, 2003), Kintsch's predication algorithm thus suggests that the meaning of a verb is more strongly influenced by semantic context than is the meaning of a noun.

There is some evidence that supports the idea that verbs are more dependent on semantic context than are nouns. First, as has been pointed out by Gentner (1981), verbs have a greater breadth of meaning than do nouns. In particular, a verb is likely to have more dictionary entries than does a noun. This appears to be true even when frequency of use is approximately matched for the nouns and the verbs. This is consistent with the hypothesis that nouns label something in the world and, thus, are stable across contexts but verbs differ in meaning, depending on the linguistic context in which they are used.

Gentner and France (1988) found additional evidence that the meanings of verbs are more dependent on linguistic context than are the meanings of nouns. They found that when a noun and a verb from a sentence were inconsistent, participants were more likely to alter the meaning of the verb than the meaning of the noun. Participants were presented with sentences in which the noun and the verb were semantically inconsistent (e.g., The butterfly pondered). For each sentence, the participant was asked to paraphrase the sentence. In these paraphrases, the participants changed the verb so as to be consistent with the noun (e.g., turning pondered into hovered) more often than they changed the noun so as to be consistent with the verb (e.g., turning butterfly into $a$ person wearing bright clothes).

If the meanings of verbs depend on semantic context, this may have implications for memory. In particular, the fact that the same verb may have different meanings on different occasions may make verbs difficult to remember. There is growing evidence that verbs are not remembered as well as nouns. For example, Engelkamp et al. (1990) tested participants' memory for lists of nouns and lists of verbs and found that the participants recalled more nouns than verbs. Horowitz and Prytulak (1969) and Clark (1966) both found that participants did not recall as many verbs as subject nouns or object nouns from transitive sentences. Earles and Kersten (2000) found that verb pairs were more difficult to recall than noun pairs, and Earles et al. (1999) found that verbs from verb-noun pairs (e.g., wave hand) were recalled less often than the nouns from the same pairs. There is also evidence that verbs are not recognized as well as nouns (Reynolds \& Flagg, 1976). Mohr, Engelkamp, and Zimmer (1989) and Engelkamp and Zimmer (1995) both found that in a recognition test for action phrases, participants were less likely to notice a change in the verb from encoding to retrieval than to notice a change in the noun.

If the meanings of verbs are dependent on linguistic context, memory for a verb may be dependent on reinstating the same linguistic context as that present when it was originally encountered. An important part of the linguistic context for a verb is often a noun. Thus, reinstatement of the original noun that accompanied a verb may be important for recall of that verb. There is some evidence that nouns may be better cues for verbs than verbs are for nouns. In memory for complete sentences, the noun has been found to be a more important sentence cue than is the verb (Thios, 1975). In addition, Mohr (1992) found that in memory for noun-verb phrases, the noun is a better cue than the verb for memory for the 
phrases. Thus, remembering the noun may help one to remember the verb, whereas remembering the verb may not be as helpful for remembering the noun.

Although there is support for the prediction that memory for verbs will be more influenced by semantic context than is memory for nouns, nouns are also subject to contextual influence. Some authors have argued that the verb is more important to sentence meaning than is the noun. Rumelhart, Lindsay, and Norman (1972) argued that the verb makes clear the relations among the other components of a sentence and, thus, helps make sense of the other components. Thus, if a verb in a sentence is changed, the noun may no longer have the same meaning. Chafe (1970) also suggested that it is the verb that is central to the meaning of a sentence, whereas the noun is peripheral. Thus, memory for the noun may depend on reinstating the same verb at retrieval as that present during encoding.

There is considerable evidence that memory for nouns is influenced by semantic context. In particular, in order to test the encoding specificity principle of Tulving and Thomson (1973), Light and Carter-Sobell (1970) presented participants with lists of adjective-noun pairs. For each noun, two adjectives were chosen so that each suggested a different meaning of the noun. During encoding, one of these adjectives was presented with each noun. At recognition, the participants were more likely to correctly recognize the nouns when they were accompanied by an adjective that suggested the same meaning as the one that had been suggested during encoding. When a different adjective was presented, the participants had difficulty recognizing the noun. The encoding specificity effect has been demonstrated repeatedly over the last 30 years (e.g., Earles, Smith, \& Park, 1994; Park, Puglisi, Smith, \& Dudley, 1987; Puglisi, Park, Smith, \& Dudley, 1988). Memory for nouns, therefore, is influenced by the semantic context present at encoding and retrieval.

Thus, memory for both nouns and verbs is dependent on the context in which the words are encoded and on the context in which the words are retrieved. We predicted, however, on the basis of the theories of Gentner (1981, 1982; Gentner \& Boroditsky, 2001), Kersten (1998, 2003), and Kintsch (2001), that memory for verbs would be much more dependent on semantic context than memory for nouns would be. To test this prediction, we presented adult participants with a series of intransitive sentences (e.g., The ball bounced) and asked them to remember either the noun or the verb from each sentence. Intransitive sentences were employed for two reasons. First, intransitive sentences are methodologically convenient in that they contain a single noun and a single verb, thus allowing a relatively clean comparison of memory for these two types of words. Second, such sentences represent the simplest possible sentence structure in the English language and, thus, make a good starting point for an investigation of the effects of semantic context on memory for nouns and verbs. Further discussion of the generalizability of the present results to other types of nouns and verbs can be found in the General Discussion section.

After viewing a series of such intransitive sentences, the participants were tested on their ability to recognize the nouns or the verbs in these sentences. In particular, the participants were presented with sentences and were asked whether they had previously seen either the noun or the verb from each sentence. Some sentences were identical to those seen at encoding, some involved an old noun and a new verb, some involved a new noun and an old verb, and some involved a new noun and a new verb. It was predicted that the participants would have greater difficulty recognizing a word in the context of a new word than in the context of the same word as that presented at encoding. It was predicted that this effect would be larger in memory for verbs than in memory for nouns, however, providing evidence that semantic context influences memory for verbs more than it influences memory for nouns.

\section{EXPERIMENT 1}

\section{Method}

\section{Participants}

Ninety-six undergraduate students from Florida Atlantic University received course credit in a general psychology class for participation.

\section{Materials}

Encoding lists. There were four lists of 60 sentences, each of which contained a noun and a verb (e.g., The ball bounced). First, two lists of 60 sentences were composed. Each noun-verb pair in List 1 (e.g., ball bounced) corresponded to a noun-verb pair in List 2 (e.g., quarter rolled), so that the noun from the sentence in each list (e.g., ball) could be paired with both of the verbs (e.g., bounced or rolled) and the verb from the sentence in each list (e.g., bounced) could be paired with both nouns (e.g., ball or quarter). The words in each list were matched in frequency according to the norms provided by Francis and Kučera (1982). In List 1, the nouns had an average frequency of 72 , and the verbs had an average frequency of 81 . In List 2, the nouns had an average frequency of 72 , and the verbs had an average frequency of 80 . The frequencies for the nouns were not significantly different from the frequencies for the verbs $(t<1)$. These encoding lists are provided in the Appendix.

Although the nouns and the verbs in Lists 1 and 2 were matched in terms of frequency, we could not match the nouns and the verbs on every possible feature, so we wanted to take steps to ensure that any results that we obtained were not due to the particular nouns and verbs that we used. Thus, two additional lists of 60 sentences were created in the same manner as were Lists 1 and 2. Again, the average frequency for the nouns $(M=54)$ was not significantly different from that of the verbs $(M=48 ; t<1)$. The sentences from List 3 and List 4 are also provided in the Appendix. There was one random presentation order for each list.

Recognition lists. There were four lists of 60 recognition sentences corresponding to Lists 1 and 2 and four lists of 60 recognition sentences corresponding to Lists 3 and 4. Each list consisted of 15 sentences that were identical to ones seen at encoding, 15 sentences containing a familiar noun but a new verb, 15 sentences containing a familiar verb but a new noun, and 15 entirely new sentences. Across the four recognition lists, the two nouns and two verbs from each corresponding pair of sentences were presented in all possible combinations. For example, if the encoding sentence was The ball bounced, one retrieval list contained The ball bounced, one contained The ball rolled, one contained The quarter bounced, and 
one contained The quarter rolled. For each list, there was one random order of retrieval sentences, with the condition that no more than 3 sentences of the same type were presented in a row.

\section{Design}

There were two independent variables, word type and retrieval context. Word type was manipulated between participants. The participants were asked to remember either the nouns or the verbs from the sentences. Retrieval context was manipulated within participants. For participants who tried to remember nouns, the verb presented at retrieval was the same as or different from that presented at encoding, and for participants who tried to remember verbs, the noun at retrieval was the same as or different from that at encoding.

\section{Procedure}

The participants viewed each of 60 sentences on a computer screen for $7 \mathrm{sec}$. One fourth of the participants received each of the four encoding lists. Half of the participants presented with each encoding list were asked to remember the nouns from the sentences, and half were asked to remember the verbs. Following the presentation of each sentence, the participants were asked to rate "How often do you see this happen?" on a scale of 1 (almost never) to 5 (very often). This question was presented in order to encourage the participants to read and process the entire sentence.

Following the presentation of the 60 sentences, the participants were given a 15 -min intervening task. The participants saw 68 vocabulary words on the computer screen for $10 \mathrm{sec}$ each. Along with each word, they received 4 other words and were asked to choose the word that was most similar in meaning to the presented word. The correct answer was shown following each response. This intervening task was used to prevent rehearsal and to make the recognition task more difficult.

During retrieval, those participants who had been asked to remember nouns were tested on their ability to recognize those nouns, and those participants who had been asked to remember verbs were tested on their ability to recognize those verbs. One quarter of the participants from each encoding condition received each of the four retrieval lists. The participants saw each sentence on the computer screen. Those in the noun condition pressed "y" if the noun had been presented at encoding and " $n$ " if it had not. Those in the verb condition pressed " $y$ " if the verb had been presented at encoding and " $n$ " if it had not. The participants were given as much time as they needed to respond to each sentence.

\section{Results}

Two measures of recognition sensitivity were computed for each participant. One measure represented a participant's ability to recognize a word when it was presented in the same semantic context as that at encoding. For this measure, we first computed the proportion of hits to previously encountered words that were presented in the same context as that at encoding. We then computed the proportion of false alarms to new words that were presented along with a familiar context word. These proportions can be seen in Table 1. We then used these proportions to compute $A^{\prime}$, a measure of recognition sensitivity, according to the formulas provided by Rae (1976). This was used as our measure of recognition sensitivity for words presented in the same semantic context as that at encoding.

The second measure represented a participant's ability to recognize a word when it was presented in a different semantic context from that seen at encoding. In particular, we first computed the proportion of hits to previously encountered words that were presented in a new semantic context. We then computed the proportion of false alarms to new words that were presented along with an unfamiliar context word. These proportions can also be seen in Table 1. We then used these proportions to compute $A^{\prime}$ as our measure of recognition sensitivity for words presented in a different semantic context from that seen at encoding.

The two $A^{\prime}$ measures of recognition sensitivity are depicted in Figure 1, both for the participants in the noun condition and for the participants in the verb condition. A $2 \times 2$ analysis of variance (ANOVA) was conducted on these measures, with word type (noun vs. verb) as a between-subjects factor and retrieval context (same vs. different) as a within-subjects factor. An alpha level of .05 was adopted for this and all other analyses. This analysis revealed a main effect of word type $[F(1,94)=$ $\left.37.33, M S_{\mathrm{e}}=0.011, p<.001\right]$, with better recognition sensitivity for nouns than for verbs. It also revealed a main effect of retrieval context $\left[F(1,94)=16.88, M S_{\mathrm{e}}=\right.$ $0.007, p<.001]$ with better recognition sensitivity for words presented in the same context as that at encoding than for words presented in a different semantic context.

These main effects, however, were moderated by a significant interaction of word type and retrieval context $\left[F(1,94)=6.24, M S_{\mathrm{e}}=0.007, p=.014\right]$. In particular, recognition sensitivity for verbs was significantly better when verbs were presented in the same context as that at encoding than when they were presented in a different semantic context $[t(47)=3.78, p<.001]$. Recognition sensitivity for nouns, on the other hand, was not significantly different in the two semantic contexts $[t(47)=$ $1.66, p>.10]$.

\section{Discussion}

As was predicted, semantic context had a larger effect on memory for verbs than on memory for nouns. The participants were much more likely to recognize a verb if the verb was accompanied by the same noun as that presented at encoding. In contrast, the participants recognized a noun about equally well regardless of whether or not it was accompanied by the same verb as that presented at encoding. These findings are consistent with the theories of Gentner and Boroditsky (2001), Kersten (1998, 2003), and Kintsch (2001) that the meanings of verbs are more strongly dependent on linguistic context than are the meanings of nouns.

There remains an alternative hypothesis for these results, however. In particular, because of the standard word order of English sentences, nouns always appeared before verbs in our stimuli. As a result, it remains possible that some of the participants who were instructed to remember the noun in each sentence merely read up to the noun and then stopped reading, whereas the participants who were instructed to remember the verb had to read to the end of each sentence. This would result in a smaller effect of semantic context on memory for nouns 
Table 1

Hits and False Alarms for Each Condition

\begin{tabular}{|c|c|c|c|c|c|c|}
\hline \multirow[b]{2}{*}{ Condition } & \multicolumn{2}{|c|}{ Experiment 1} & \multicolumn{2}{|c|}{ Experiment 2} & \multicolumn{2}{|c|}{ Experiment 3} \\
\hline & $M$ & $S D$ & $M$ & $S D$ & $M$ & $S D$ \\
\hline \multicolumn{7}{|c|}{ Encode nouns/retrieve nouns } \\
\hline \multicolumn{7}{|c|}{ Hits } \\
\hline Same & .91 & .09 & .91 & .13 & .94 & .08 \\
\hline Different & .86 & .13 & .84 & .15 & .84 & .15 \\
\hline None & NA & NA & NA & NA & .82 & .12 \\
\hline \multicolumn{7}{|l|}{ False alarms } \\
\hline Same & .22 & .15 & .22 & .16 & .19 & .17 \\
\hline Different & .21 & .15 & .20 & .14 & .18 & .16 \\
\hline None & NA & NA & NA & NA & .17 & .15 \\
\hline \multicolumn{7}{|c|}{ Encode verbs/retrieve verbs } \\
\hline \multicolumn{7}{|c|}{ Hits } \\
\hline Same & .89 & .12 & .89 & .08 & .88 & .10 \\
\hline Different & .65 & .20 & .66 & .19 & .70 & .17 \\
\hline None & NA & NA & NA & NA & .70 & .15 \\
\hline \multicolumn{7}{|l|}{ False alarms } \\
\hline Same & .35 & .19 & .29 & .17 & .30 & .17 \\
\hline Different & .28 & .19 & .23 & .18 & .29 & .18 \\
\hline None & NA & NA & NA & NA & .30 & .15 \\
\hline \multicolumn{7}{|c|}{ Encode verbs/retrieve nouns } \\
\hline \multicolumn{7}{|c|}{ Hits } \\
\hline Same & NA & NA & .90 & .08 & .91 & .09 \\
\hline Different & NA & NA & .78 & .16 & .86 & .11 \\
\hline None & NA & NA & NA & NA & .81 & .13 \\
\hline \multicolumn{7}{|l|}{ False alarms } \\
\hline Same & NA & NA & .23 & .15 & .25 & .19 \\
\hline Different & NA & NA & .15 & .13 & .19 & .14 \\
\hline None & NA & NA & NA & NA & .22 & .11 \\
\hline \multicolumn{7}{|c|}{ Encode nouns/retrieve verbs } \\
\hline \multicolumn{7}{|c|}{ Hits } \\
\hline Same & NA & NA & NA & NA & .90 & .10 \\
\hline Different & NA & NA & NA & NA & .63 & .15 \\
\hline None & NA & NA & NA & NA & .70 & .15 \\
\hline \multicolumn{7}{|l|}{ False alarms } \\
\hline Same & NA & NA & NA & NA & .35 & .17 \\
\hline Different & NA & NA & NA & NA & .29 & .20 \\
\hline None & NA & NA & NA & NA & .36 & .17 \\
\hline
\end{tabular}

than on memory for verbs, because the participants who were instructed to remember the noun would not necessarily have read the verb that went with each noun.

One approach to addressing this alternative hypothesis would be to present sentences in a noncanonical word order, such as Bounce was what the ball did or Bouncing was done by the ball. Such sentences would likely be confusing to participants, however, and thus we opted not to pursue this strategy. Instead, the strategy we adopted was to instruct some participants to remember the verb in each sentence, and then to test them on their memory for the noun. This procedure encouraged the participants to read to the end of the sentence. The performance of these participants was compared with the performance of the participants who were instructed to remember nouns and were later tested on memory for nouns and with the performance of the participants who were instructed to remember verbs and were later tested on memory for verbs.

Thus, the encoding instructions given to this new group of participants were identical to those given to the participants who were instructed to remember verbs and were later tested on their memory for verbs. If the results of Experiment 1 reflected solely a tendency for the participants in the noun condition not to read the verb in each sentence during encoding, the participants in Experiment 2 who were instructed to remember verbs and were later tested on memory for nouns would be expected to show the same effects of semantic context as would the participants who were instructed to remember verbs and were later tested on memory for verbs. In fact, the effects of context might be predicted to be even larger for this new group of participants, because attention would be focused on the context word. If the theories of Gentner and Boroditsky (2001), Kersten (1998, 2003), and Kintsch (2001) are correct, however, the effects of semantic context should be greater for verbs than for nouns, even when the encoding instructions were the same in the two cases.

\section{EXPERIMENT 2}

\section{Method}

\section{Participants}

Ninety-six undergraduate students from Florida Atlantic University received course credit in a general psychology course for participation. 


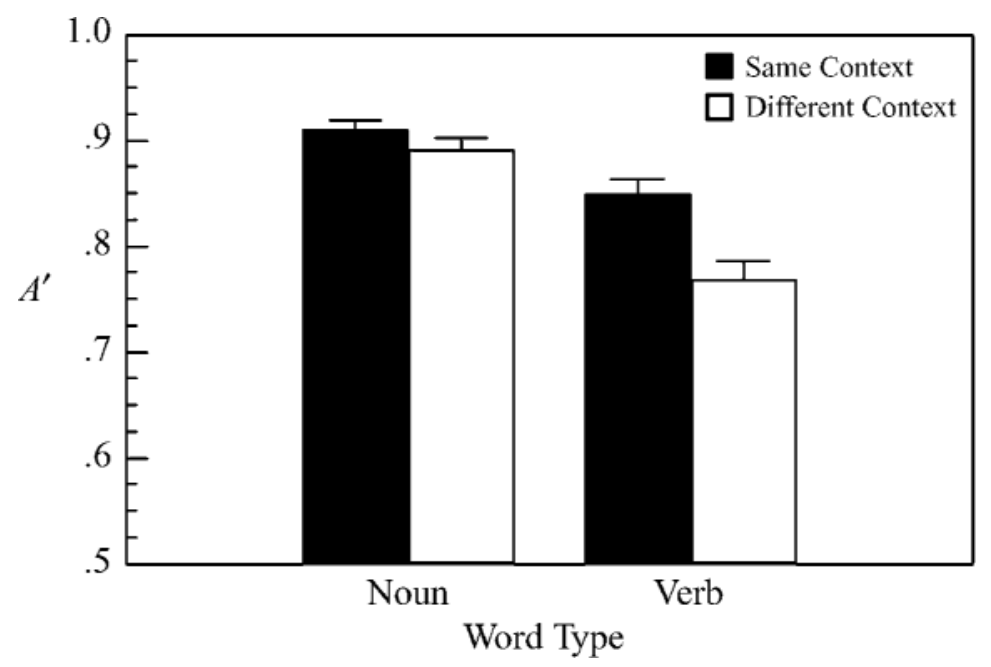

Figure 1. $A^{\prime}$ measures of recognition sensitivity in Experiment 1. In the samecontext condition, $A^{\prime}$ was computed using the proportion of hits to old words presented in the same semantic context as that in which they had appeared at encoding and the proportion of false alarms to new words presented along with a familiar context word. In the different-context condition, $A^{\prime}$ was computed using the proportion of hits to old words presented in a new semantic context and the proportion of false alarms to new words presented along with an unfamiliar context word. An $A^{\prime}$ of .5 represents chance performance, whereas an $A^{\prime}$ of 1.0 represents perfect performance. Error bars represent standard errors.

\section{Materials}

There were two encoding lists of 88 sentences, each containing one noun and one verb. These sentences were taken from the lists generated for Experiment 1. Four recognition lists were created using the same method as that in Experiment 1.

\section{Design}

The design of Experiment 2 was similar to that of Experiment 1, except for the addition of a condition in which the participants were asked to remember the verbs but were later tested on their memory for the nouns. The participants were thus assigned to one of three conditions. The participants in the encode-noun/retrieve-noun condition were asked to remember the noun from each sentence and were later tested on their memory for the nouns. The participants in the encode-verb/retrieve-noun condition were asked to remember the verb from each sentence but were later tested on the memory for the nouns. The participants in the encode-verb/retrieve-verb condition were asked to remember the verbs from each sentence and were later tested on their memory for the verbs.

\section{Procedure}

Half of the participants viewed each of the two encoding lists. As in Experiment 1, each sentence was presented for $7 \mathrm{sec}$ on a computer screen, and the participants were asked to rate how often they saw each event. Following encoding, the participants received the 15 -min vocabulary test and were then given a recognition test. For the participants in the encode-noun/retrieve-noun and the encodeverb/retrieve-verb conditions, the recognition test was the same as that in Experiment 1. Those participants in the encode-verb/ retrievenoun condition were told at retrieval that although they had previously been asked to learn the verbs, they were now going to be tested on their memory for the nouns. During the recognition test, the participants in all three conditions saw 22 sentences that were the same as those presented at encoding, 22 with the same noun but a different verb, 22 with the same verb but a different noun, and 22 new items.

\section{Results}

Three participants were dropped from the analysis of Experiment 2 because they failed to make more hits than false alarms over the entire sequence of trials. One of these participants was in the encode-noun/retrieve-noun condition, and 2 were in the encode-verb/retrieve-verb condition. The proportions of hits and false alarms of the remaining participants are listed in Table 1 , and $A^{\prime}$ measures of recognition sensitivity are depicted in Figure 2. An ANOVA was conducted on recognition sensitivity, with condition (encode-noun/retrieve-noun vs. encodeverb/retrieve-noun vs. encode-verb/retrieve-verb) as a between-subjects independent variable and retrieval context (same vs. different) as a within-subjects independent variable. This analysis revealed a significant main effect of condition $\left[F(2,90)=3.56, M S_{\mathrm{e}}=0.012, p=.033\right]$. Post hoc Tukey HSD tests failed to reveal any significant differences between the three conditions, although there was a trend for poorer performance in the encode-verb/ retrieve-verb condition than in either the encode-noun/ retrieve-noun condition $(q=3.34, p=.057)$ or the encode-verb/retrieve-noun condition $(q=3.33, p=.057)$. There was also a significant main effect of retrieval context $\left[F(1,90)=31.01, M S_{\mathrm{e}}=0.003, p<.001\right]$, with better recognition sensitivity when a word was presented in the same context as that at encoding than when a word was presented in a different context.

These main effects, however, were moderated by a significant interaction of condition and retrieval context $\left[F(2,90)=4.61, M S_{\mathrm{e}}=0.003, p=.012\right]$. In order to interpret this interaction, the interaction of condition and 


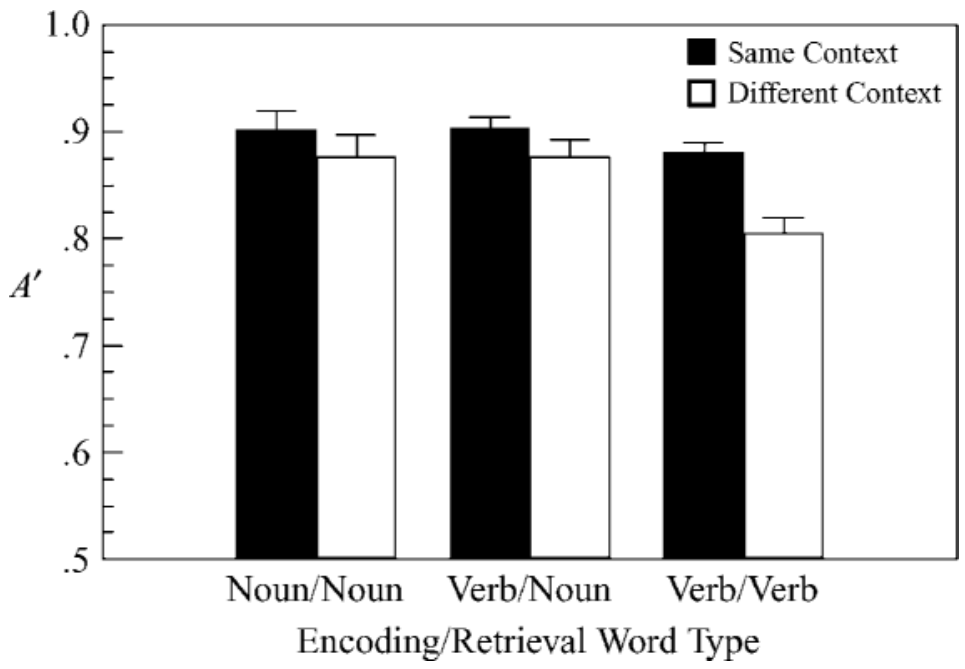

Figure 2. $A^{\prime}$ measures of recognition sensitivity in Experiment 2. In the samecontext condition, $A^{\prime}$ was computed using the proportion of hits to old words presented in the same semantic context as that in which they had appeared at encoding and the proportion of false alarms to new words presented along with a familiar context word. In the different-context condition, $A^{\prime}$ was computed using the proportion of hits to old words presented in a new semantic context and the proportion of false alarms to new words presented along with an unfamiliar context word. An $A^{\prime}$ of .5 represents chance performance, whereas an $A^{\prime}$ of 1.0 represents perfect performance. Error bars represent standard errors.

retrieval context was examined for all possible pairs of conditions. When recognition sensitivity between the encode-noun/retrieve-noun and the encode-verb/retrieveverb conditions was compared, there was a significant interaction of condition and retrieval context $[F(1,59)=$ $\left.7.54, M S_{\mathrm{e}}=0.003, p=.008\right]$. In particular, there was a significant effect of retrieval context on performance in the encode-verb/retrieve-verb condition $[t(29)=5.59$, $p<.001]$, whereas this effect only approached significance in the encode-noun/retrieve-noun condition $[t(30)=$ $1.97, p=.058]$. This replicated the finding from Experiment 1 that the effects of semantic context were larger for verbs than for nouns.

There was also a significant interaction of condition and retrieval context when the encode-verb/retrievenoun and the encode-verb/retrieve-verb conditions were compared $\left[F(1,60)=6.40, M S_{\mathrm{e}}=0.003, p=.014\right]$. In particular, whereas the effect of retrieval context was significant in the encode-verb/retrieve-verb condition $[t(29)=5.59, p<.001]$, this effect only approached significance in the encode-verb/retrieve-noun condition $[t(31)=2.01, p=.053]$. There was, thus, a larger effect of semantic context on memory for verbs than on memory for nouns, even when the encoding instructions were the same in the two cases.

There was not a significant interaction of condition and retrieval context with the contrast between the encodenoun/retrieve-noun and the encode-verb/retrieve-noun conditions $\left[F(1,61)=0.02, M S_{\mathrm{e}}=0.003, p>.10\right]$. Thus, encouraging the participants to read to the end of each sentence by instructing them to remember the verb did not increase the size of the semantic context effect on memory for nouns.

\section{Discussion}

The results of Experiment 2 provided further support for the hypothesis that memory for verbs is more dependent on semantic context than is memory for nouns. The effects of semantic context were larger for verbs than for nouns, even when the encoding instructions encouraged the participants in the noun condition to read to the end of each sentence. The results of Experiment 2 thus ruled out the hypothesis that the reduced effect of semantic context on memory for nouns in Experiment 1 was due to the participants who were instructed to remember nouns failing to read the verb that went with each noun.

Recognition sensitivity for nouns was, in fact, almost identical regardless of whether the participants were initially instructed to remember nouns or verbs, suggesting that the participants in the two conditions used similar encoding strategies. A likely explanation is that the orienting task of asking the participants to rate how often they had witnessed a particular event encouraged the participants to form a mental image of that event and it was this mental image that formed the basis for later successful recognition of the words, regardless of whether the participants were instructed to remember nouns or verbs. If the participants were later presented with a word in the same context as that at encoding, this would encourage the creation of a similar mental image, allow- 
ing a participant to recognize having seen the word before. If a word were presented in a different semantic context, this would generally still allow successful recognition in the case of nouns, because the mental image of an object elicited by a noun in one semantic context would still be similar to the mental image of the object elicited by that same noun in a different semantic context. This would be less successful in the case of verbs, because the mental image of an action elicited by a verb in one semantic context would often be very different from the mental image of an action elicited by the verb in a different semantic context. The results of Experiment 2 are thus quite consistent with the prediction of the theories of Gentner and Boroditsky (2001), Kersten (1998, 2003), and Kintsch (2001) that the meanings of verbs are more dependent on semantic context than are the meanings of nouns.

\section{EXPERIMENT 3}

Experiment 3 was designed to explore the mechanisms underlying why words are remembered better in the same context than in a different context. One possible mechanism involves facilitated memory for the target word in the same context as a result of reinstating at retrieval the same meaning of the target word as that presented at encoding. The second possible mechanism involves interference in memory for the target word in a different context, due to bringing to mind at retrieval a different meaning of the word than that present at encoding.

The first two experiments do not allow one to distinguish between these two mechanisms, because they both predict better memory in the same context than in a different context. Experiment 3 was designed to provide such a test by comparing performance in these two conditions with performance in a condition in which no semantic context was present at retrieval. In particular, the participants were presented at encoding with a nounverb pair, but at retrieval they were simply presented with an isolated word, either a noun or a verb, and were asked whether or not they had seen this word before. If the advantage of the same-context condition over the different-context condition reflects facilitation from reinstating the same meaning of the target word at retrieval as at encoding, performance in the no-context condition should be the same as that in the different-context condition. In particular, in neither the no-context condition nor the different-context condition was the encoded meaning of the target word implicated by the retrieval context. If, on the other hand, the advantage of the same-context condition over the different-context condition reflects interference from bringing to mind a competing meaning of the target word, performance in the no-context condition should be the same as that in the same-context condition, because in neither the no-context condition nor the same-context condition was a competing meaning of the target word implicated by the retrieval context. Of course, a third possibility is that the advantage of the same-context condition over the different-context condi- tion is a result of both mechanisms. If this is the case, performance in the no-context condition should be intermediate between that in the same-context condition and that in the different-context condition.

Experiment 3 was also designed to further test the notion that the effects of semantic context in the present experiments did not result from an explicit attempt to remember the noun or the verb in each sentence. Semantic context effects may, instead, have fallen naturally out of the reading and processing of each sentence, as dictated by the orienting task of rating how often one had witnessed the event described by each sentence. To test this idea, half of the participants in Experiment 3 were instructed to encode the noun in each sentence, whereas half were instructed to encode the verb. Furthermore, within each of these two groups of participants, half of the participants were tested on memory for nouns, and half were tested on memory for verbs. If the effects of semantic context result from the processing of each sentence associated with the orienting task, the size of the semantic context effect should be unrelated to the type of word that a participant is instructed to encode. Instead, the size of the semantic context effect should depend only on the type of word one is asked to retrieve. In particular, effects of semantic context should be larger when the participants are tested on memory for verbs than when they are tested on memory for nouns, regardless of which type of word the participants were initially instructed to encode.

\section{Method}

\section{Participants}

One hundred forty-four undergraduate students from Florida Atlantic University received course credit in a general psychology course for participation.

\section{Materials}

There were two lists of 90 sentences, each containing one noun and one verb. These sentences were taken from the lists generated for the first experiment.

\section{Design}

There were three independent variables: encoding word type, retrieval word type, and retrieval context. Encoding word type was manipulated between participants. The participants were asked to remember either the nouns or the verbs from the sentences. Retrieval word type was also manipulated between participants. The participants were tested on their memory for either nouns or verbs. Finally, retrieval context was manipulated within participants. For participants who were tested on their memory for nouns, in one third of the trials the verb presented at retrieval was the same as that at encoding, in one third of the trials the verb presented at retrieval was different from that at encoding, and for one third of the trials the participant received no verb. For the participants who were tested on their memory for verbs, the noun at retrieval was the same as that at encoding for one third of the trials, was different from that at encoding for one third of the trials, and was not present for one third of the trials.

\section{Procedure}

The participants viewed each of the 90 sentences on a computer screen for $7 \mathrm{sec}$. Half of the participants viewed each of the two lists. As in the previous two experiments, following each sentence, 
the participants rated how often they had seen the described event happen. After the entire list had been presented, the participants completed the vocabulary test and were then given a self-paced recognition test.

There were six different recognition lists, and an equal number of participants received each list. For those participants tested on memory for nouns, each recognition list contained 15 verb-noun pairs that were the same as those at encoding, 15 pairs that contained the same noun but a different verb, 15 pairs that contained the same verb but a different noun, 15 completely new verb-noun pairs, 15 nouns that were the same as those at encoding but were not paired with verbs, and 15 new nouns that were not paired with verbs. Those participants tested on memory for verbs received 15 verb-noun pairs that were the same as those at encoding, 15 pairs that contained the same noun but a different verb, 15 pairs that contained the same verb but a different noun, 15 completely new verbnoun pairs, 15 verbs that were the same as those at encoding but were not paired with nouns, and 15 new verbs that were not paired with nouns. The recognition procedure was the same as that in Experiments 1 and 2 .

\section{Results}

The proportions of hits and false alarms in Experiment 3 are listed in Table 1, and $A^{\prime}$ measures of recognition sensitivity are depicted in Figure 3. An ANOVA was conducted on recognition sensitivity, with encoding word type (noun vs. verb) and retrieval word type (noun vs. verb) as between-subjects independent variables and retrieval context (same vs. none vs. different) as a withinsubjects independent variable. This analysis revealed a significant main effect of retrieval word type $[F(1,140)=$ 70.64, $\left.M S_{\mathrm{e}}=0.014, p<.001\right]$, with better recognition sensitivity for nouns than for verbs. The main effect of encoding word type did not approach significance $\left[F(1,140)=0.24, M S_{\mathrm{e}}=0.014, p>.10\right]$, nor were there any significant interactions involving encoding word type (all $p \mathrm{~s}>.10)$.

There was a significant main effect of retrieval context $\left[F(2,280)=35.27, M S_{\mathrm{e}}=0.005, p<.001\right]$. Post hoc Tukey HSD tests revealed that recognition sensitivity was better in the same-context condition than in either the no-context condition $(q=11.02, p<.01)$ or the different-context condition $(q=9.36, p<.01)$, whereas there was not a significant difference in performance between the latter two conditions $(q=1.65, p>.10)$. These results thus suggest that the performance advantage of the same-context condition over the different-context condition reflects facilitation from reinstating at retrieval the same meaning of the target word as that presented at encoding.

As was predicted, there was also a significantinteraction of retrieval word type and retrieval context $[F(2,280)=$ $\left.12.08, M S_{\mathrm{e}}=0.005, p<.001\right]$. In order to interpret this interaction, the interaction of retrieval word type and retrieval context was examined for all possible pairs of retrieval contexts. In replication of Experiments 1 and 2, when recognition sensitivity in the same and the different retrieval contexts was compared, there was a signif-

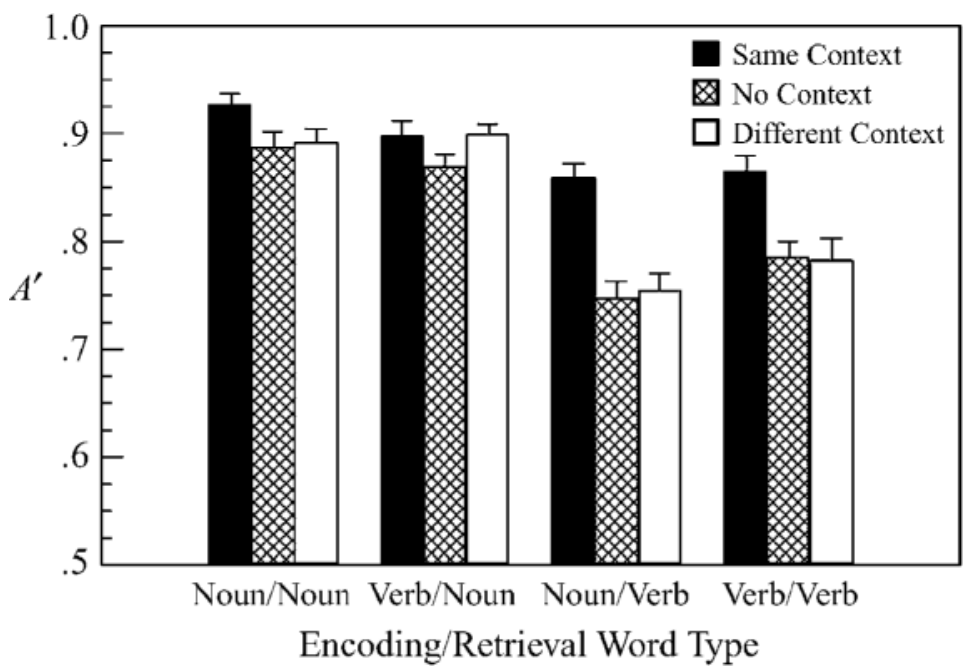

Figure 3. $A^{\prime}$ measures of recognition sensitivity in Experiment 3. In the samecontext condition, $A^{\prime}$ was computed using the proportion of hits to old words presented in the same semantic context as that in which they had appeared at encoding and the proportion of false alarms to new words presented along with a familiar context word. In the no-context condition, $A^{\prime}$ was computed using the proportion of hits to old words presented in isolation and the proportion of false alarms to new words presented in isolation. In the different-context condition, $A^{\prime}$ was computed using the proportion of hits to old words presented in a new semantic context and the proportion of false alarms to new words presented along with an unfamiliar context word. An $A^{\prime}$ of .5 represents chance performance, whereas an $A^{\prime}$ of 1.0 represents perfect performance. Error bars represent standard errors. 
icant interaction of retrieval context and retrieval word type $\left[F(1,142)=26.83, M S_{\mathrm{e}}=0.004, p<.001\right]$. In particular, recognition sensitivity for verbs was significantly better in the same context than in the different context $[t(71)=7.87, p<.001]$, whereas this effect was much smaller and only approached significance for nouns $[t(71)=1.84, p=.07]$.

When recognition sensitivity in the same and none retrieval contexts was compared, there was also a significant interaction of retrieval context and retrieval word type $\left[F(1,142)=15.19, M S_{\mathrm{e}}=0.005, p<.001\right]$. In particular, recognition sensitivity for verbs was significantly better in the same-context condition than in the no-context condition $[t(71)=8.06, p<.001]$. This effect was also significant for nouns $[t(71)=3.20, p=.002]$ but was much smaller in magnitude.

Finally, when recognition sensitivity in the none and different retrieval contexts was compared, there was not a significant interaction of retrieval context and retrieval word type $\left[F(1,142)=0.65, M S_{\mathrm{e}}=0.006, p>.10\right]$. These results thus provide no evidence that the greater effects of semantic context on memory for verbs than on memory for nouns reflect distraction from bringing to mind alternative meanings of a verb. Instead, these effects appear to represent facilitation from reinstating at retrieval the same meaning of a verb as that presented at encoding.

\section{Discussion}

Experiment 3 provided further evidence that semantic context influences memory for verbs more than it influences memory for nouns. In addition, it provides evidence regarding the mechanisms responsible for the effects of semantic context on memory for nouns and verbs. In particular, it suggests that the effects of semantic context reflect facilitation from reinstating at retrieval the same meaning of a word as that presented at encoding. This same mechanism appears to apply in both memory for nouns and memory for verbs, but it has larger effects on memory for verbs because the meanings of verbs differ more in different semantic contexts. Experiment 3 provided no evidence of interference from bringing to mind at retrieval a different meaning of a word than that presented at encoding.

Finally, Experiment 3 provided evidence that the larger effect of semantic context on memory for verbs than on memory for nouns is not a result of the strategic encoding of the noun or the verb from each sentence but, rather, falls naturally out of the reading and processing of an entire sentence. In particular, effects of semantic context were larger on memory for verbs than on memory for nouns, regardless of whether the participants had initially been instructed to encode nouns or verbs. This finding suggests that the orienting task of rating how often one had witnessed the event described by each sentence formed the basis for the effects of semantic context in these experiments, given that this orienting task was shared by the two encoding conditions. Thus, one may expect larger effects of semantic context on memory for verbs than on memory for nouns under any conditions that require the active reading and processing of a sentence.

\section{GENERAL DISCUSSION}

The present experiments provide evidence that memory for verbs is more dependent on semantic context than is memory for nouns. Experiment 1 revealed that the participants were much more likely to remember a verb if it were presented in the same semantic context at encoding and at retrieval, whereas this effect was much smaller for nouns. Experiment 2 demonstrated this same effect even when the participants in the noun and the verb conditions were given the same instructions at encoding, ruling out the hypothesis that the larger semantic context effect in memory for verbs than in memory for nouns was a result of a failure by the participants who were instructed to remember nouns to encode the verb that went with each noun. Finally, Experiment 3 demonstrated that the advantage in memory for words presented in the same context over words presented in a different context was a result of facilitation from reinstating at retrieval the same meaning of the target word as that presented at encoding.

These results are consistent with the natural partitions/ relational relativity theory proposed by Gentner (1981, 1982; Gentner \& Boroditsky, 2001). According to this theory, nouns tend to label objects that are prelinguistically isolated from the rest of an event. Because the meanings of nouns are grounded in nonlinguistic categories, they do not tend to change very much in different linguistic contexts. The meanings of verbs and other relational terms, on the other hand, are not as well grounded in nonlinguistic categories. Thus, the meanings of verbs are suggested to differ in different linguistic contexts, and memory for verbs would be expected to depend greatly on context.

The present results are also consistent with the theories of Kersten $(1998,2003)$ and Kintsch (2001). These theories suggest two different but related mechanisms for how the same verb can mean different things in the context of different nouns. In Kersten (1998, 2003), different nouns are associated with different manners of motion, and thus the same verb selects different manners of motion when used in conjunction with different nouns. In Kintsch, different nouns are associated with different verbs, each of which represents a particular kind of motion. Thus, the same verb means different things in the context of different nouns because different nouns bring to mind different sets of associated verbs, which bias the computation of the vector representing the meaning of the noun-verb combination. The present results suggest that Kintsch's predication algorithm more accurately captures the meanings of noun-verb combinations than do earlier theories of LSA (e.g., Landauer et al., 1997), in which such combinations are merely represented by the centroid of the vectors representing the noun and the verb.

The present findings on noun and verb memory may be related to recent findings by Kersten and Smith (2002) on noun and verb learning. They found that 3.5- to 
4-year-old children learning a novel verb attended just as strongly to the appearance of an object as to its motion. This strategy makes sense if one assumes that the same verb means different things in the context of different objects. In particular, in order to determine what a verb may mean in the context of a particular object, one has to learn about the object and the kinds of motion of which it is capable. In contrast, children learning a novel noun attended almost exclusively to the appearance of an object and ignored its motion. This strategy also makes sense if one assumes that the meanings of nouns are stable across motion contexts. In particular, one can determine the meaning of a noun simply by focusing on an object. Thus, children's learning strategies for the two types of words may reflect the nature of the meanings conveyed by the two types of words.

\section{Generalizability to Other Types of Nouns and Verbs}

The nouns and verbs in the present experiments were always presented in the context of intransitive sentences, in which the noun played the role of grammatical subject and the verb referred to an action or state of that subject. Such sentences describe a very basic, frequently occurring type of event, and thus phenomena associated with this type of sentence are of considerable theoretical interest. The restrictions placed on the nouns and verbs used in these experiments meant that they had characteristics that are not true of all nouns and verbs, however, and thus it remains to be seen whether the present results will generalize to other types of nouns and verbs.

First, the fact that nouns played the role of grammatical subject meant that nearly all of the nouns used in these experiments referred to concrete objects, whereas the verbs referred to the actions and states of these objects. According to Gentner's (1981, 1982; Gentner \& Boroditsky, 2001) natural partitions theory, objects are prelinguistically isolated from the rest of an event, anchoring the meanings of referring nouns in the physical world and, thus, making them less susceptible to alteration. In contrast, states and actions can be construed in many different ways, making verb meanings more susceptible to alteration. Not all nouns refer to objects, however, and not all verbs refer to actions and states. In particular, as has been pointed out by Maratsos and Chalkley (1980), there is considerable overlap in the meanings conveyed by nouns and verbs, with some nouns (e.g., an attack) referring to actions and some verbs (e.g., to vacuum) implicating the presence of a particular object. Thus, it is unclear to what extent the present results reflect a distinction between nouns and verbs and to what extent they reflect a distinction between object and nonobject terms. As has been pointed out by a number of researchers (e.g., Brown, 1957; Maratsos, 1990), however, concrete objects represent the core of the noun grammatical category, whereas objects are not central to the verb grammatical category, and thus there is reason to believe that a distinction between object and nonobject terms will generalize to a distinction between nouns and verbs.

Second, the fact that nouns played the role of grammatical subject in these experiments meant that nouns always preceded verbs in the presented sentences. Although Experiments 2 and 3 demonstrated that even participants who were instructed to encode nouns continued on to read the verb in each sentence, it still remains the case that the verbs were always read in the context of having just read a noun, whereas the nouns were read without having just read a verb. That subject nouns precede verbs is of course a general feature of the English language, and thus the phenomena observed in the present experiments would be expected to generalize to the real-world processing of English intransitive sentences. It remains to be seen, however, whether the present results with subject nouns will generalize to object nouns, which typically follow, rather than precede, the verb in an English sentence.

Despite these differences between subject nouns and object nouns, there are two reasons to believe that the present results will generalize to object nouns. First, object nouns, as well as subject nouns, are recalled better than verbs (e.g., Earles et al., 1999). To explain this finding, Earles et al. (1999) proposed that the meaning brought to mind by a verb at retrieval is often different from the meaning brought to mind at encoding, making it difficult to recall that one has seen that verb before. If this explanation is correct, the better recall of object nouns than of verbs would suggest that the meanings of object nouns, as well as subject nouns, are less subject to contextual influence than are the meanings of verbs. Second, Gentner and France (1988) found that verbs were more likely than nouns to change in meaning when the two were semantically inconsistent, regardless of whether the nouns preceded or followed the verbs. This combination of findings suggests that nouns are generally more stable in meaning than are verbs, making memory for nouns more robust to changes in semantic context regardless of the order in which nouns and verbs appear in a sentence.

A third characteristic of the present nouns and verbs that is not true of all nouns and verbs involves the hierarchical level of the words. Nearly all of the nouns used in the present research were basic-level nouns (see Rosch, Mervis, Gray, Johnson, \& Boyes-Braem, 1976). In contrast, Kersten and Billman (1997) have proposed that most verbs, such as the ones used in the present study, are more similar to superordinate than to basic-level nouns. In particular, whereas people have detailed knowledge of specific event categories (e.g., The toddler fell), there is no verb in the language that specifically conveys one of these event categories. A given verb (e.g., fell) may instead apply to a broad range of these categories (e.g., toddlerfell, leaves fell, temperature fell, stock market fell, etc.) that differ widely in their implications. Verbs may thus be similar to superordinate nouns (e.g., vehicle) that refer to a broad range of different objects 
(e.g., car, plane, tricycle, etc.). If this theory is correct, the effects of semantic context on memory for superordinate nouns may be just as large as those on memory for verbs. For example, if a participant were to be presented with the noun vehicle in the context of the verb rolled, he or she might later have a difficult time recognizing that noun in the context of a different verb, such as flew. Even if this is the case, however, basic-level nouns are preferentially used in most situations (Rosch et al., 1976), and thus the present results will still be representative of the majority of real-world noun and verb use.

A final possibility is that, despite the differences between the present nouns and verbs and other types of nouns and verbs, memory for verbs will always be more dependent on semantic context than will memory for nouns. This prediction stems from the different syntactic roles of nouns and verbs in a sentence. The role of a noun in a sentence is to make reference to something in the world, whereas the role of the verb is to specify the relations among the various noun arguments. The role of the verb as organizer of the nouns in a sentence may require that it be adjustable for changes in those nouns, just as a good supervisor may organize a set of employees differently depending on the qualities of those employees. If semantic adjustability is a necessary requirement for being a verb, verbs may be more susceptible than nouns to changes in semantic context, regardless of the nature of the nouns and verbs involved.

\section{REFERENCES}

BRown, R. (1957). Linguistic determinism and the part of speech. Journal of Abnormal \& Social Psychology, 55, 1-5.

CHAFE, W. L. (1970). Meaning and the structure of language. Chicago: University of Chicago Press.

CLARK, H. H. (1966). The prediction of recall patterns in simple active sentences. Journal of Verbal Learning \& Verbal Behavior, 5, 99-106.

EARLES, J. L., \& Kersten, A. W. (2000). Adult age differences in memory for verbs and nouns. Aging, Neuroscience, \& Cognition, 7, 130139.

Earles, J. L., Kersten, A. W., Turner, J. M., \& McMullen, J. (1999). Influences of age, performance, and item relatedness on verbatim and gist recall of verb-noun pairs. Journal of General Psychology, 126, 97-110.

EARles, J. L., SMith, A. D., \& PARK, D. C. (1994). Age differences in the effects of facilitating and distracting context on memory performance. Aging \& Cognition, 2, 141-151.

ENGELKAMP, J., \& ZIMMER, H. D. (1995). Similarity of movement in recognition of self-performed tasks and of verbal tasks. British Journal of Psychology, 86, 241-249.

ENGELKAMP, J., ZIMMER, H. D., \& MoHR, G. (1990). Differential memory effects of concrete nouns and action verbs. Zeitschrift für Psychologie, 198, 189-216.

FRANCIS, W. N., \& KUČERA, H. (1982). Frequency analysis of English usage: Lexicon and grammar. Boston: Houghton Mifflin.

GENTNER, D. (1981). Some interesting differences between verbs and nouns. Cognition \& Brain Theory, 4, 161-178.

Gentner, D. (1982). Why nouns are learned before verbs: Linguistic relativity versus natural partitioning. In S. A. Kuczaj (Ed.), Language development: Vol. 2. Language, thought, and culture (pp. 301-334). Hillsdale, NJ: Erlbaum.

GENTNER, D., \& BORODITSKy, L. (2001). Individuation, relativity, and early word learning. In M. Bowerman \& S. C. Levinson (Eds.), Language acquisition and conceptual development (pp. 215-256). Cambridge: Cambridge University Press.

Gentner, D., \& FrAnCE, I. M. (1988). The verb mutability effect: Studies of the combinatorial semantics of nouns and verbs. In S. L. Small, G. W. Cottrell, \& M. K. Tanenhaus (Eds.), Lexical ambiguity resolution: Perspectives from psycholinguistics, neuropsychology, and artificial intelligence (pp. 343-382). San Mateo, CA: Morgan Kaufmann.

Horowitz, L. M., \& PrytulaK, L. S. (1969). Redintegrative memory. Psychological Review, 76, 519-531.

Kersten, A. W. (1998). A division of labor between nouns and verbs in the representation of motion. Journal of Experimental Psychology: General, 127, 34-54.

KERSTEN, A. W. (2003). Verbs and nouns convey different types of motion in event descriptions. Linguistics, 41, 917-945.

Kersten, A. W., \& Billman, D. O. (1997). Event category learning. Journal of Experimental Psychology: Learning, Memory, \& Cognition, 23, 638-658.

Kersten, A. W., \& SMith, L. B. (2002). Attention to novel objects during verb learning. Child Development, 73, 93-109.

KINTSCH, W. (2001). Predication. Cognitive Science, 25, 173-202.

Landauer, T. K., Laham, D., Rehder, B., \& Schreiner, M. E. (1997). How well can passage meaning be derived without using word order? A comparison of latent semantic analysis and humans. In M. G. Shafto \& P. Langley (Eds.), Proceedings of the 19th Annual Meeting of the Cognitive Science Society (pp. 412-417). Mahwah, NJ: Erlbaum.

Light, L. L., \& CARTER-SobelL,L. (1970). Effects of changed semantic context on recognition memory. Journal of Verbal Learning \& Verbal Behavior, 9, 1-11.

MARATSOS, M. P. (1990). Are actions to verbs as objects are to nouns? On the differential semantic bases of form, class, category. Linguistics, 28, 1351-1379.

Maratsos, M.P., \& Chalkley, M. A. (1980). The internal language of children's syntax: The ontogenesis and representation of syntactic categories. In K. E. Nelson (Ed.), Children's language(Vol. 2, pp. 127 214). New York: Gardner.

MoHr, G. (1992). Retrieval of action phrases: The efficacy of verb cues and noun cues. Zeitschrift für Psychologie, 200, 363-370.

Mohr, G., EngelKamp, J., \& ZIMMER, H. D. (1989). Recall and recognition of self-performed acts. Psychological Research, 51, 181-187.

Park, D. C., Puglisi, J. T., Smith, A. D., \& Dudley, W. N. (1987). Cue utilization and encoding specificity in picture recognition by older adults. Journal of Gerontology, 42, 423-425.

Puglisi, J. T., PARK, D. C., Smith, A. D., \& Dudley, W. N. (1988). Age differences in encoding specificity. Journal of Gerontology, 43, 145 150 .

RAE, G. (1976). Table of $A^{\prime}$. Perceptual \& Motor Skills, 42, 98.

REYNOLDS, A. G., \& FLAGG, P. W. (1976). Recognition memory for elements of sentences. Memory \& Cognition, 4, 422-432.

Rosch, E. H., Mervis, C. B., Gray, W. D., Johnson, D. M., \& BoyesBraem, P. (1976). Basic objects in natural categories. Cognitive Psychology, 8, 382-439.

Rumelhart, D. E., Lindsay, P. H., \& NoRman, D. A. (1972). A process model for long-term memory. In E. Tulving \& W. Donaldson (Eds.), Organization of memory (pp. 197-246). New York: Academic Press.

THIOS, S. J. (1975). Memory for general and specific sentences. Memory \& Cognition, $3,75-77$.

Tulving, E., \& ThOmson, D. M. (1973). Encoding specificity and retrieval processes in episodic memory. Psychological Review, 80, 352373. 
APPENDIX

Encoding Lists in Experiment 1

\begin{tabular}{|c|c|c|c|}
\hline \multicolumn{2}{|c|}{ Presentation List 1} & \multicolumn{2}{|c|}{ Presentation List 2} \\
\hline puppies & played & brothers & wrestled \\
\hline athlete & spit & llama & kicked \\
\hline mother & rested & pig & fed \\
\hline hammer & pounded & drummer & struck \\
\hline rabbit & listened & frog & hopped \\
\hline trunk & locked & door & slammed \\
\hline speaker & crackled & circuit & blew \\
\hline duck & swam & shark & bit \\
\hline canary & sat & choir & sang \\
\hline coat & warmed & blanket & covered \\
\hline tree & grew & banana & rotted \\
\hline friend & phoned & marketer & annoyed \\
\hline cows & roamed & salesman & chewed \\
\hline soldiers & marched & band & assembled \\
\hline doctor & mended & tailor & cut \\
\hline monkey & hung & vine & climbed \\
\hline petals & flew & tourists & scattered \\
\hline aroma & hinted & evidence & offended \\
\hline volunteer & ate & waiter & served \\
\hline fine & accumulated & snow & decreased \\
\hline winter & lingered & bird & returned \\
\hline sprinter & accelerated & car & hesitated \\
\hline magician & practiced & lawyer & deceived \\
\hline quarter & bounced & ball & rolled \\
\hline clamp & tightened & fist & gripped \\
\hline dancer & slipped & tire & spun \\
\hline make-up & hid & deer & ran \\
\hline wax & melted & ice & dripped \\
\hline $\log$ & sank & boat & drifted \\
\hline mirror & cracked & brick & chipped \\
\hline key & broke & glasses & fit \\
\hline witness & observed & journalist & reported \\
\hline teachers & discussed & politician & argued \\
\hline kite & landed & plane & soared \\
\hline fish & smelled & antelope & froze \\
\hline salt & dissolved & medicine & spilled \\
\hline leaves & fell & temperature & dropped \\
\hline $\operatorname{dog}$ & rescued & police & arrived \\
\hline commander & signaled & flag & waved \\
\hline actor & changed & light & danced \\
\hline army & attacked & tiger & waited \\
\hline spring & coiled & snake & stretched \\
\hline alarm & rang & telephone & startled \\
\hline finger & bent & needle & poked \\
\hline paper & tore & cloth & dried \\
\hline building & collapsed & bridge & shook \\
\hline blood & leaked & memo & circulated \\
\hline nurse & stayed & relatives & visited \\
\hline restaurant & closed & flower & opened \\
\hline chemist & mixed & chef & stirred \\
\hline lion & roared & hurricane & threatened \\
\hline horse & jumped & boy & paced \\
\hline senator & voted & citizens & protested \\
\hline toddler & stumbled & clown & smiled \\
\hline thunder & clapped & audience & rumbled \\
\hline steam & rose & sun & burned \\
\hline engine & raced & runner & choked \\
\hline picture & disturbed & memory & faded \\
\hline cat & slept & prisoner & escaped \\
\hline table & stood & judge & overturned \\
\hline
\end{tabular}


APPENDIX (Continued)

\begin{tabular}{|c|c|c|c|}
\hline \multicolumn{2}{|c|}{ Presentation List 3} & \multicolumn{2}{|c|}{ Presentation List 4} \\
\hline duck & waddled & penguin & bobbed \\
\hline trucks & collided & athletes & exited \\
\hline quarter & bounced & ball & rolled \\
\hline stone & skipped & sister & wobbled \\
\hline family & immigrated & scientist & visited \\
\hline donkey & trotted & greyhound & lurched \\
\hline boat & sank & $\log$ & drifted \\
\hline gopher & burrowed & baby & scooted \\
\hline soldiers & marched & band & strolled \\
\hline voters & vacated & enemies & assembled \\
\hline runner & pranced & pony & staggered \\
\hline grandmother & jogged & tourists & slipped \\
\hline fly & landed & plane & circled \\
\hline jockey & dismounted & gymnast & leapt \\
\hline lion & trudged & hunter & prowled \\
\hline butterfly & fluttered & hummingbird & flew \\
\hline boy & jumped & bear & danced \\
\hline ants & invaded & armies & dispersed \\
\hline gorilla & stomped & elephant & paced \\
\hline spaceship & ascended & mountaineer & plunged \\
\hline rabbit & swam & frog & hopped \\
\hline hound & backtracked & agents & approached \\
\hline peacock & strutted & outfielder & zigzagged \\
\hline nail & penetrated & bullet & fell \\
\hline birds & migrated & tribe & returned \\
\hline wheel & spun & ballerina & turned \\
\hline passengers & boarded & pilots & evacuated \\
\hline toddler & stumbled & clown & crawled \\
\hline panther & dashed & scout & crept \\
\hline camel & departed & ship & traversed \\
\hline waves & receded & crowd & joined \\
\hline $\operatorname{dog}$ & paddled & fisherman & waded \\
\hline kitten & plummeted & climber & retreated \\
\hline balloon & dropped & helicopter & lifted \\
\hline acrobats & emerged & swimmers & dived \\
\hline champion & skated & suitor & rowed \\
\hline animals & circulated & captain & disembarked \\
\hline monkey & swung & cousin & rocked \\
\hline prisoner & escaped & tiger & entered \\
\hline snake & slithered & monster & coiled \\
\hline troops & advanced & actors & gathered \\
\hline king & swaggered & warrior & slid \\
\hline rat & scampered & bunny & tunneled \\
\hline horse & galloped & player & limped \\
\hline cat & descended & hiker & climbed \\
\hline reporters & converged & rivers & separated \\
\hline brothers & romped & puppies & sprinted \\
\hline farmer & walked & oxen & shuffled \\
\hline salesman & pursued & cowboy & fled \\
\hline pedestrian & crossed & spider & reversed \\
\hline deer & ran & girl & bounded \\
\hline thief & tiptoed & mother & lumbered \\
\hline leaves & scattered & protesters & lingered \\
\hline weeds & tumbled & boxer & swayed \\
\hline guests & intruded & audience & vanished \\
\hline bus & passed & biker & merged \\
\hline train & arrived & jogger & proceeded \\
\hline dancers & scrambled & students & waltzed \\
\hline nurse & appeared & magician & withdrew \\
\hline princess & rose & sun & disappeared \\
\hline
\end{tabular}

